\title{
Women's Intentions to Engage in Risk-Reducing Behaviours after Receiving Personal Ovarian Cancer Risk Information: An Experimental Survey Study
}

\author{
Ailish Gallagher ${ }^{1}$, Jo Waller ${ }^{2}$, Ranjit Manchanda ${ }^{3,4}\left(\mathbb{D}\right.$, Ian Jacobs ${ }^{5}$ and Saskia Sanderson ${ }^{1,6, *(\mathbb{D})}$ \\ 1 Research Department of Behavioural Science and Health, University College London, Gower Street, \\ London WC1E 6BT, UK; Ailish.gallagher@gstt.nhs.uk \\ 2 Cancer Prevention Group, School of Cancer \& Pharmaceutical Sciences, King's College London, \\ Guy's Hospital, Great Maze Pond, London SE1 9RT, UK; jo.waller@kcl.ac.uk \\ 3 Wolfson Institute of Preventive Medicine, Barts Cancer Institute, Queen Mary University of London, \\ Charterhouse Square, London EC1M 6BQ, UK; r.manchanda@qmul.ac.uk \\ 4 Department of Gynaecological Oncology, Barts Health NHS Trust, London EC1A 7BE, UK \\ 5 Department of Women's Health, University of New South Wales, Australia, Level 1, Chancellery Building, \\ Sydney 2052, Australia; i.jacobs@unsw.edu.au \\ 6 Early Disease Detection Research Project UK (EDDRP UK), 2 Redman Place, London E20 1JQ, UK \\ * Correspondence: saskia.sanderson@ucl.ac.uk
}

Received: 5 October 2020; Accepted: 24 November 2020; Published: 27 November 2020

Simple Summary: Risk stratification using genetic testing to identify women at increased risk of ovarian cancer may increase the number of patients to whom risk-reducing surgery (e.g., salpingo-oophorectomy) may be offered. However, little is known about public acceptability of such approaches. Our online experimental survey aimed to explore whether women aged 45-75 in the general population are willing to undergo ovarian cancer risk assessment, including genetic testing, and whether women's potential acceptance of risk-reducing surgery differs depending on their estimated risk. We looked at whether psychological and cognitive factors mediated women's decision-making. The majority of participants would be interested in having genetic testing. In response to our hypothetical scenarios, a substantial proportion of participants were open to the idea of surgery to reduce risk of ovarian cancer, even if their absolute lifetime risk is only increased from $2 \%$ to 5 or $10 \%$.

\begin{abstract}
Risk stratification using genetic and/or other types of information could identify women at increased ovarian cancer risk. The aim of this study was to examine women's potential reactions to ovarian cancer risk stratification. A total of 1017 women aged 45-75 years took part in an online experimental survey. Women were randomly assigned to one of three experimental conditions describing hypothetical personal results from ovarian cancer risk stratification, and asked to imagine they had received one of three results: (a) 5\% lifetime risk due to single nucleotide polymorphisms (SNPs) and lifestyle factors; (b) 10\% lifetime risk due to SNPs and lifestyle factors; (c) 10\% lifetime risk due to a single rare mutation in a gene. Results: $83 \%$ of women indicated interest in having ovarian cancer risk assessment. After receiving their hypothetical risk estimates, $29 \%$ of women stated they would have risk-reducing surgery. Choosing risk-reducing surgery over other behavioural responses was associated with having higher surgery self-efficacy and perceived response-efficacy, but not with perceptions of disease threat, i.e., perceived risk or severity, or with experimental condition. A substantial proportion of women age 45-75 years may be open to the idea of surgery to reduce risk of ovarian cancer, even if their absolute lifetime risk is only increased to as little as 5 or $10 \%$.
\end{abstract}

Keywords: risk stratification; genomics; questionnaires; attitudes 


\section{Introduction}

Ovarian cancer is the sixth most common cancer among women in the UK. The general population lifetime risk of developing ovarian cancer is approximately $2 \%$, and incidence is predicted to rise by $26 \%$ in the UK, $14 \%$ in Europe, and by $55 \%$ worldwide over the next two decades [1]. The risk of ovarian cancer rises with age, increasing significantly in women over 45 years [2]. DNA variants in a number of cancer susceptibility genes are known to be associated with ovarian cancer: women with a high penetrance genetic variant, such as a $B R C A 1$ or $B R C A 2$ mutation, are considered to be at high risk for developing breast and ovarian cancer [3-5]. Historically, genetic testing for ovarian cancer risk has been clinically indicated only for women with a strong family history of breast and/or ovarian cancer. However, using a family history based approach misses over half the cancer susceptibility gene (CSG) carriers at risk [6,7], and is associated with restricted access and limited utilization of genetic testing [8]. Additionally, the majority of cases of ovarian cancer do not occur in affected families [9]. There is increasing interest in the idea of adopting a risk-stratified approach to ovarian cancer prevention by offering genetic testing to all women regardless of family history [10-12].

In addition to rare variants of high penetrance, genome-wide association studies have to date identified a number of common single nucleotide polymorphisms (SNPs) associated with slightly increased risk of ovarian cancer [13]. SNP-based information and certain lifestyle factors each increase ovarian cancer risk by a small amount individually, but this becomes clinically significant when the information is combined, e.g., from $2 \%$ to between $5 \%$ and $10 \%$ lifetime risk $[9,14,15]$. Surgical prevention has been shown to be cost-effective at the $4-5 \%$ ovarian cancer risk threshold $[16,17]$. Newer risk models and recently validated intermediate risk genes can identify individuals at these risk thresholds. Risk stratification using multigene testing to identify women at increased risk of ovarian cancer is potentially more cost- and time-effective than single gene testing and increases the number of patients to whom risk-reducing surgery (e.g., salpingo-oophorectomy) may be offered [18]. While clinical practice has gradually begun to change [19], data on public acceptability of such approaches are limited.

An initial quantitative study assessing attitudes towards population-based genetic testing for ovarian cancer risk in a general population sample found high levels of support for risk-stratified ovarian cancer screening based on prior genetic risk assessment [20]. There is good evidence to suggest that population-wide genetic testing for ovarian cancer is acceptable, feasible and cost-effective amongst Ashkenazi Jewish populations [6,7,21-23]. Preliminary data from the general population also indicate that population-based personalised ovarian cancer risk stratification is feasible, acceptable, has high satisfaction, reduces cancer worry/risk perception, and does not negatively impact psychological health or quality of life [12].

Bilateral risk-reducing salpingo-oophorectomy (surgical removal of the ovaries and fallopian tubes, hereafter referred to as "risk-reducing salpingo-oophorectomy" or "RRSO") is currently recommended as the main and most effective preventative strategy for ovarian cancer in women at increased risk of ovarian cancer such as $B R C A$ mutation carriers. RRSO can reduce ovarian cancer risk by $85-90 \%$ [24]. Traditionally the most common group of women undergoing surgical prevention have been $B R C A$ carriers, who have a $17-44 \%$ lifetime risk of ovarian cancer $[5,25]$. In the UK, women with an estimated lifetime ovarian cancer risk of greater than $10 \%$, who have completed their families, have traditionally been offered risk-reducing surgery [15]. Undertaking surgery on the basis of family history alone in the absence of a known mutation (at lower than BRCA levels of risk) has thus been clinical practice in the UK and other countries for many years [25,26]. Recently, the $10 \%$ threshold was relaxed to $4-5 \%[14,15]$. A number of new ovarian cancer risk genes have been identified, such as RAD51C (lifetime risk 11\%) [27], RAD51D (lifetime risk 13\%), PALB2 (lifetime risk 5\%) [28], and BRIP1 (lifetime risk 5.8\%) [29], testing for which is part of routine clinical practice. RRSO is now offered and being undertaken for these CSGs too. Thus a number of clinical teams now offer RRSO to women in the "intermediate" risk category (5-10\%) as well as those in the "high" risk category (over 10\%) [15]. Additionally, more complex models using SNP profiles, in combination with other epidemiological 
and genetic risk factors, are being validated, which will provide absolute lifetime risk estimates in these ranges in the not too distant future [12].

National screening programmes for ovarian cancer are unavailable. In a large randomised control trial designed to establish the effect of early detection by ovarian screening in the general low-risk population, no conclusive significant impact on mortality from ovarian cancer was found [30], and definitive mortality data are awaited in 2021. Surveillance for those identified as high-risk (or in some cases moderate-to-high-risk) for ovarian cancer currently consists of serial 3-4 monthly serum CA125 (Cancer Antigen 125 protein; a tumour marker) measurement (and annual transvaginal ultrasound) aiming to detect pre-symptomatic cancer in the earlier stages and/or low volume disease where treatment is more effective [31]. This 4 monthly longitudinal CA125 biomarker driven surveillance strategy, using the risk of the ovarian cancer (ROCA) algorithm, may be beneficial in women at high risk of ovarian cancer [31]. We have shown that this is associated with a significant stage shift, which can be a surrogate for improved survival [31]. Identifying those at increased risk using a population wide risk-stratified approach may result in more timely risk reduction options and could have a significant impact on disease burden: modelling suggests that $13 \%$ of the female UK population have greater than $4 \%$ lifetime risk and $9 \%$ have greater than 5\% lifetime risk [15]. Manchanda et al. (2018) suggest that, based on National Institute for Health and Care Excellence (NICE) cost-effectiveness guidelines, risk-reducing surgery may be cost effective for postmenopausal women over the age of 50, with a lifetime ovarian cancer risk of $\geq 5 \%$. Wider implementation of targeted surgical prevention for women at greater than $4-5 \%$ lifetime risk threshold provides a huge opportunity for cost-effective targeted primary prevention.

Offering risk stratification to women in the general population, including communicating personal ovarian cancer risk information and offering risk-reducing surgery, has the potential to be a feasible way to reduce ovarian cancer mortality and reduce the population burden of the disease. However, risk stratification will only lead to improved ovarian cancer prevention and early diagnosis if women whose results indicate increased risk take action to reduce their risk. Women with a family history of breast and ovarian cancer have been found to opt for risk reduction surgery, e.g., among BRCA1 and $B R C A 2$ mutation carriers, the majority underwent risk-reducing surgery (salpingo-oophorectomy) after their risk was communicated to them [25,32]. However, although quite a lot is known about how genetic risk information impacts psychological wellbeing and behaviours among women from families affected with ovarian (and/or breast) cancer, less is known about how women in the wider non-Jewish population might react to being informed they have an increased genetic risk of ovarian cancer [33-37]. Further research is needed to determine how women in the general population might respond if presented with ovarian cancer risk information indicating they are at high risk based on genetic as well as other risk factors.

Based on research prior to 2016, the evidence does not support the hypothesis that communicating CSG-based risk estimates motivates lifestyle behaviour changes [33,38]. CSG-based risk information also has not been associated with negative psychological outcomes [7,33,38,39]. More recently, a nested study within the Predicting Risk of Cancer at Screening (PROCAS) study was conducted comparing the psychological impact of providing women with personalised breast cancer risk estimates based on: (a) the Tyrer-Cuzick (T-C) risk algorithm including breast density, or (b) T-C including breast density plus SNPs, versus (c) comparison women awaiting results. This study found little evidence of either psychological harm or of differences between women provided with risk estimates based on SNPs versus others. However, women categorised as high-risk were excluded from the study, so no conclusions could be drawn regarding high-risk results specifically. It remains to be seen whether the source of the risk may have impacted psychological factors or if it had an effect on acceptance of the risk information in this study [40]. In another recent study that examined the impact of returning secondary findings (including $B R C A 1 / 2$ ) from genomic sequencing to unselected populations, few adverse psychological effects were found [41]. 
As an initial step to providing some empirical data on the question of how women in the general population might respond to personal ovarian cancer risk information indicating increased risk (as against moderate risk [40]), we conducted an experimental survey study with women in the general population, using the Extended Parallel Process Model (EPPM) [42] as our theoretical framework, and to inform our selection of variables and measures. The EPPM is a social cognition model of information processing and behaviour: it posits that how individuals react to threatening information is informed by (a) their perceptions of the threat (perceived risk or susceptibility, and perceived severity), and (b) their perceptions of the recommended action to reduce the threat (self-efficacy, i.e., their confidence in their ability to carry out the recommended behaviour, and perceived response efficacy, i.e., their confidence that the recommended behaviour will effectively reduce the threat to their health).

Our specific aims were to: (1) explore whether women in the general population are willing to undergo ovarian cancer risk assessment which includes genetic testing; (2) examine whether women's potential acceptance of risk-reducing surgery differs depending on whether their estimated risk is $5 \%$ or 10\%; (3) examine whether women's potential acceptance of risk-reducing surgery differs depending on whether their estimated risk is based on a single rare genetic variant of high penetrance or a more complex combination of genetic and non-genetic factors. We also explored whether threat and efficacy cognitions mediated any observed between-group differences, and examined the associations between these cognitions (threat, efficacy) and acceptance of risk-reducing surgery in the sample overall.

\section{Results}

\subsection{Sample Characteristics}

Table 1 provides an overview of the participant characteristics. Age ranged from 45 to 75 years with a mean of $57.50(\mathrm{SD}=8.13)$. The majority were White $(95.6 \%)$ with $3.8 \%$ from other ethnic backgrounds. Educational attainment was fairly evenly split between General Certificate of Secondary Education (GCSE) or equivalent (34.6\%), A levels or equivalent $(23.8 \%)$, and undergraduate degree or equivalent $(24.1 \%)$. The majority $(85.2 \%)$ of women were either perimenopausal (beginning menopause) or post-menopausal. See Figure 1 for the Consolidated Standards of Reporting Trials (CONSORT) flow diagram of participants throughout the study.

Table 1. Sample characteristics and interest in genetic testing overall and in each randomised experimental group (total $n=1017$ ).

\begin{tabular}{|c|c|c|c|}
\hline Variables & $\begin{array}{c}\text { Group 1: } \\
\text { 5\% SNPs and Lifestyle } \\
(n=340)\end{array}$ & $\begin{array}{c}\text { Group 2: } \\
10 \% \text { SNPs and Lifestyle } \\
(n=343)\end{array}$ & $\begin{array}{l}\text { Group 3: } \\
\text { 10\% Rare Genetic Variant } \\
(n=334)\end{array}$ \\
\hline Demographics & & $n(\%)$ & \\
\hline Age Mean (SD) & $57.43(8.32)$ & $57.37(7.78)$ & $58.08(8.19)$ \\
\hline \multicolumn{4}{|l|}{ Age group } \\
\hline $45-50$ & $89(26.2)$ & $82(23.9)$ & $73(21.9)$ \\
\hline $51-55$ & $71(20.9)$ & $66(19.2)$ & $67(20.1)$ \\
\hline $56-60$ & $59(17.4)$ & $70(20.4)$ & $65(19.5)$ \\
\hline $61-65$ & $53(15.6)$ & $70(20.4)$ & $61(18.3)$ \\
\hline $66-70$ & $42(12.4)$ & $34(9.9)$ & $38(11.4)$ \\
\hline $71-75$ & $26(7.6)$ & $21(6.1)$ & $30(9.0)$ \\
\hline \multicolumn{4}{|l|}{ Ethnicity } \\
\hline White (Any background) & $327(96.2)$ & $324(94.5)$ & $321(96.1)$ \\
\hline Other ethnic group & $11(3.2)$ & $17(5.0)$ & $11(3.3)$ \\
\hline \multicolumn{4}{|l|}{ Educational Attainment } \\
\hline No Formal Qualification & $26(7.6)$ & $23(6.7)$ & $17(5.1)$ \\
\hline GCSE or equivalent & $115(33.8)$ & $126(36.7)$ & $111(33.2)$ \\
\hline A-Levels or equivalent & $75(22.1)$ & $80(23.3)$ & $87(26.0)$ \\
\hline Undergraduate degree/equivalent & $89(26.2)$ & $77(22.4)$ & $79(23.7)$ \\
\hline Postgraduate degree/equivalent & $31(9.1)$ & $30(8.7)$ & $31(9.3)$ \\
\hline Other & $4(1.2)$ & $7(2.0)$ & $9(2.7)$ \\
\hline
\end{tabular}


Table 1. Cont.

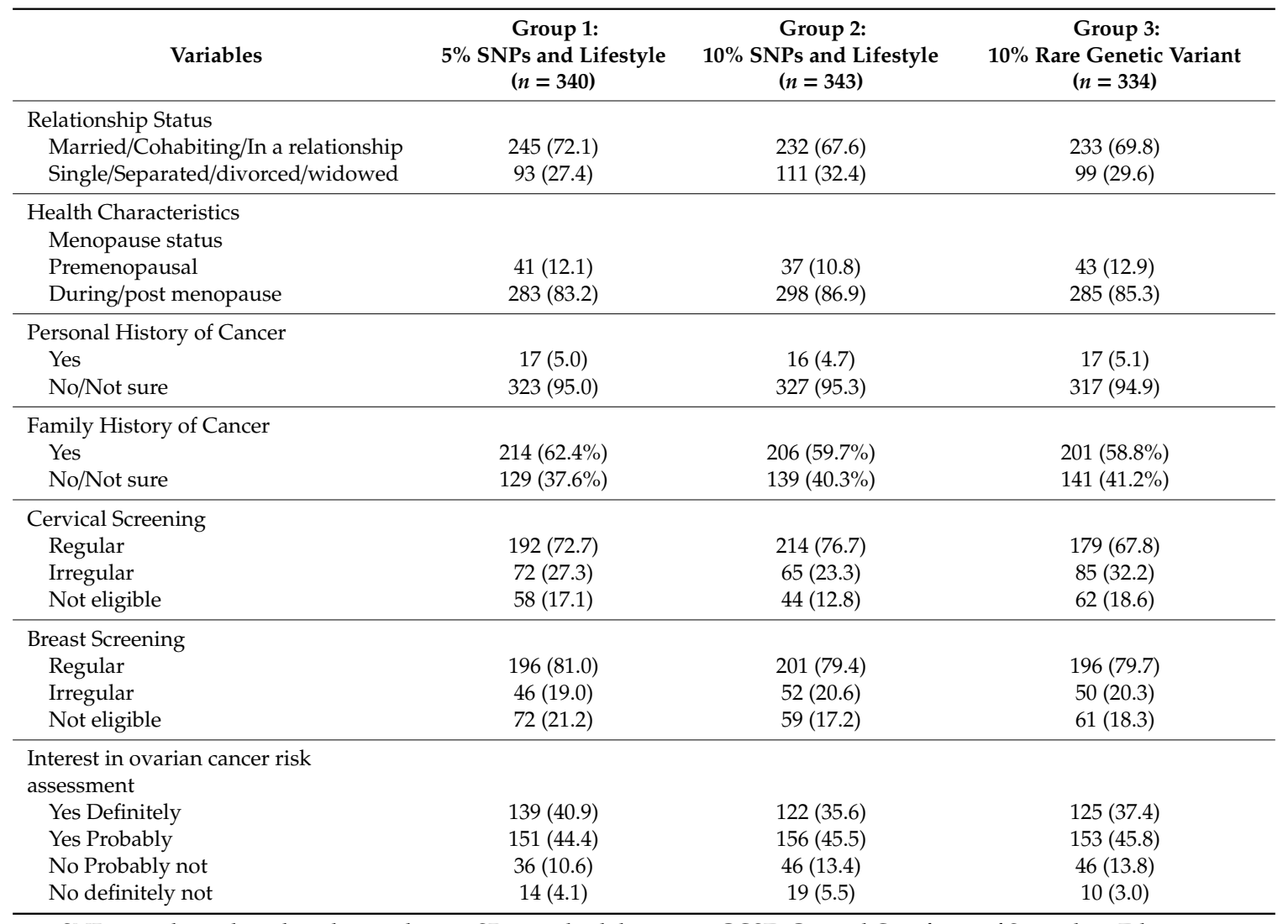

SNPs: single nucleotide polymorphisms; SD: standard deviation; GCSE: General Certificate of Secondary Education.

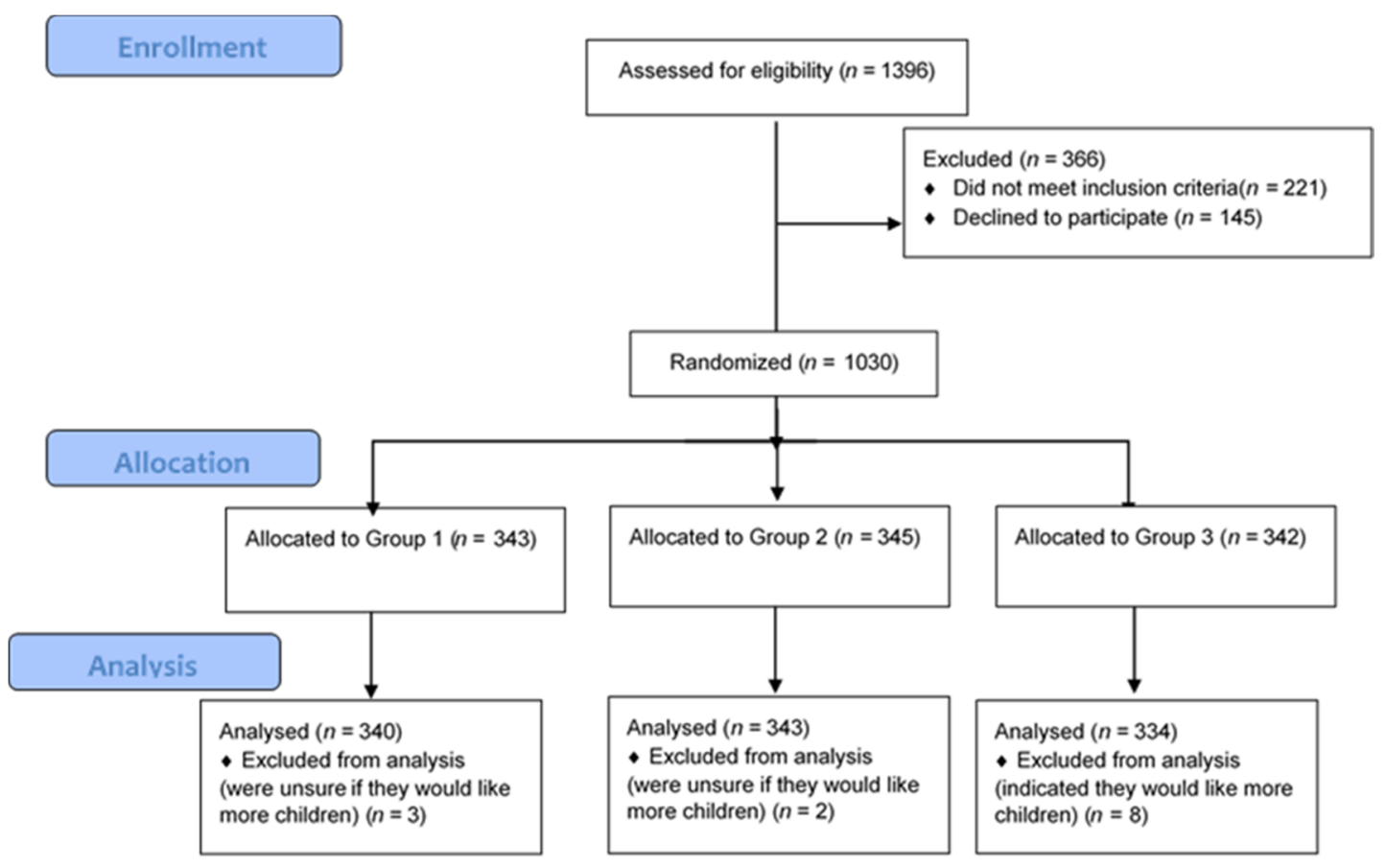

Figure 1. CONSORT 2010 Flow Diagram. 


\subsection{Interest in Ovarian Cancer Risk Assessment}

Overall, 83.2\% of women indicated they would "yes definitely" (38.0\%) or "yes probably" (45.2\%) have an ovarian cancer risk assessment if it was offered to them by their general practitioner (GP) on the National Health Service (NHS) (see Table 1 and Figure 2).

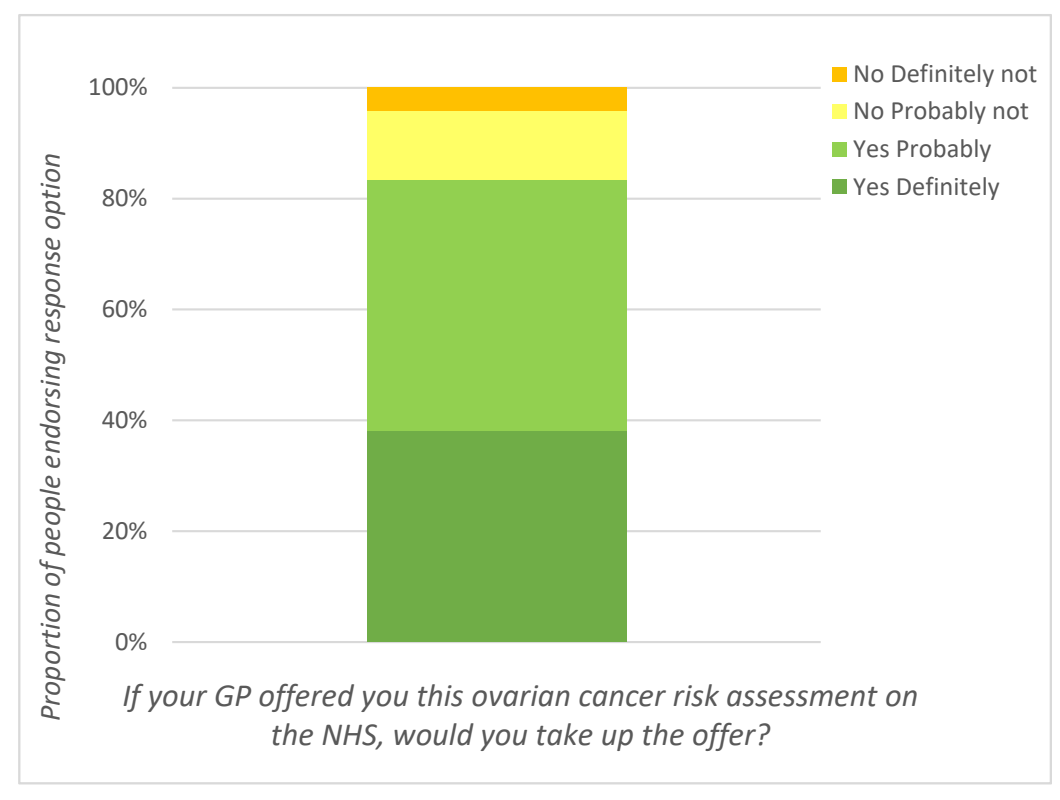

Figure 2. Interest in ovarian cancer risk assessment.

\subsection{Behavioural Response to Personalised Ovarian Cancer Risk Information}

After receiving their hypothetical risk result, $28.5 \%$ of women said they would opt for risk-reducing surgery, 33.9\% for increased surveillance (transvaginal ultrasound), and 20.9\% would make lifestyle changes (e.g., quitting smoking, maintaining a healthy weight; see Figure 3 and Table S1).

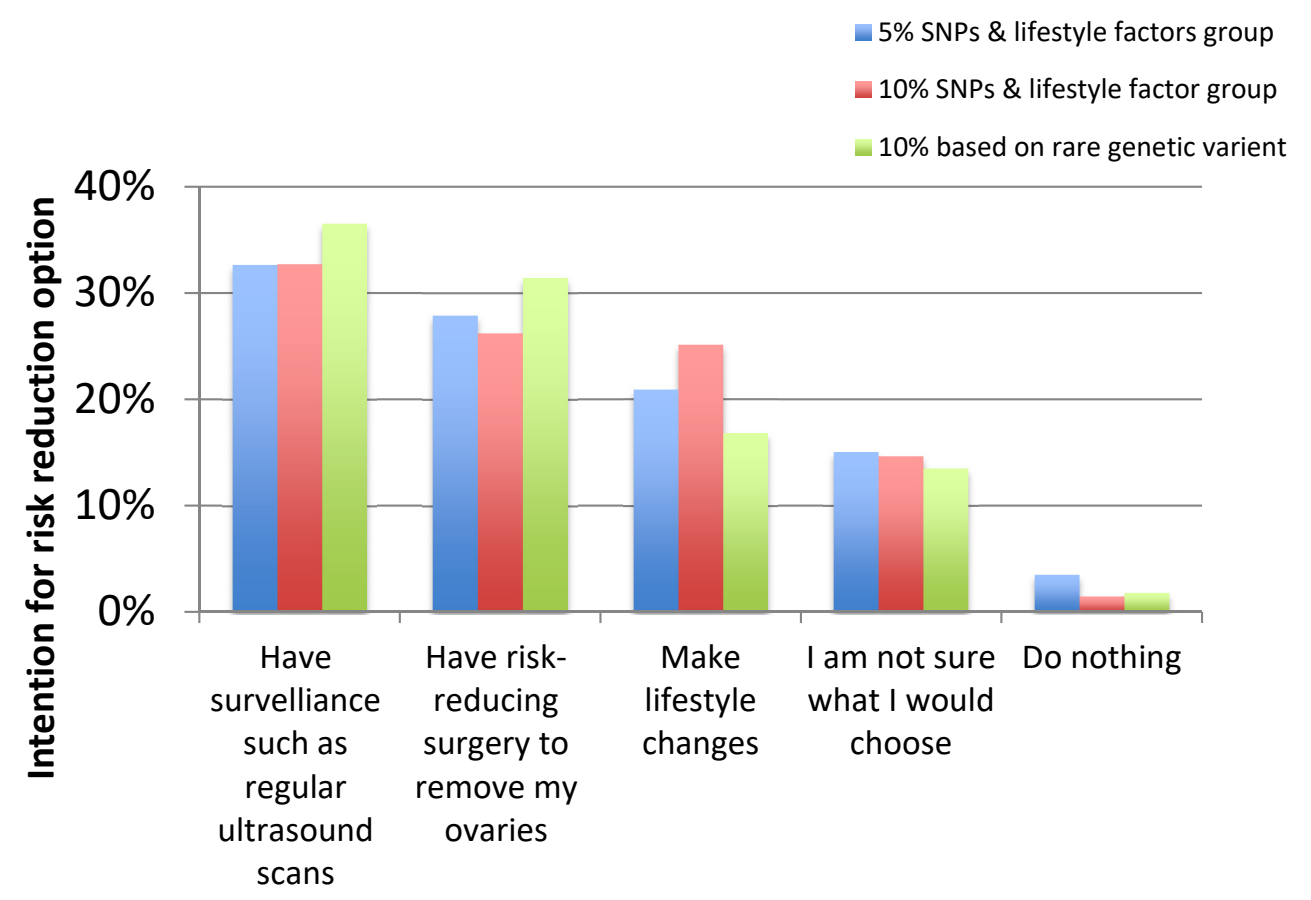

Figure 3. Behavioural intentions after exposure to hypothetical risk scenario compared between groups. 


\subsection{Differences by Experimental Condition}

Women's intentions to have risk-reducing surgery did not differ significantly between the $5 \%$ and $10 \%$ multifactorial SNPs + lifestyle groups $\left(27.9 \%\right.$ vs. $26.2 \%$, respectively) $\left(\chi^{2}(1)=0.314, p=0.61\right)$. Women who received a $10 \%$ risk result based on a rare genetic variant were no more likely to opt for RRSO over other risk-reducing options than women who received a $10 \%$ risk result based on multifactorial SNPs + lifestyle factors $\left(31.4 \%\right.$ vs. $26.2 \%$, respectively) $\left(\chi^{2}(1)=2.512, p=0.13\right)$.

\subsection{EPPM Variables}

The mean $(\mathrm{M})$ and standard deviation (SD) of the EPPM variables were: perceived risk $(\mathrm{M}=3.51$, $\mathrm{SD}=0.82)$, perceived severity $(\mathrm{M}=4.52, \mathrm{SD}=0.58)$, perceived response-efficacy $(\mathrm{M}=4.03, \mathrm{SD}=0.78)$, perceived self-efficacy $(\mathrm{M}=2.98, \mathrm{SD}=1.34)$. Means by exposure group are shown in the Supplementary Materials (Table S2).

\subsection{Intention to Have Risk-Reducing Surgery (RRSO) versus Other Risk-Management Options}

A binary logistic regression was conducted to investigate what factors were associated with hypothetical intention to have risk-reducing surgery vs. other behavioural options. Independent variables included in the model were age, ethnicity, educational attainment, previous breast and cervical screening participation, experimental group and EPPM variables (perceived risk, perceived severity, self-efficacy, perceived response-efficacy). In unadjusted analyses, women reporting higher perceived risk of ovarian cancer and higher perceived severity of ovarian cancer (i.e., the perceived threat variables), and higher surgery self-efficacy and perceived response-efficacy (i.e., variables relating to perceptions of the risk-reducing behaviour) were more likely than other women to opt for risk-reducing surgery. In the multivariable model, perceived response-efficacy (odds ratio (OR) $=2.22 ; 95 \%$ confidence interval $(\mathrm{CI}): 1.64-3.00)$ and self-efficacy $(\mathrm{OR}=1.90 ; 95 \% \mathrm{CI}: 1.63-2.22)$ remained significantly associated, whereas the perceived threat variables were no longer significantly associated, with choosing risk-reducing surgery over other behavioural options. None of the measured socio-demographic or health-related factors were significantly associated with intention to have surgery (see Table 2).

Table 2. Logistic regression predicting likelihood of intending to have risk-reducing surgery vs. other behavioural response $(n=1017)$.

\begin{tabular}{|c|c|c|c|}
\hline \multirow{3}{*}{$\begin{array}{c}\text { Variable } \\
\text { Demographic Factors }\end{array}$} & \multirow{3}{*}{$\begin{array}{c}\begin{array}{c}\text { Intention to Have } \\
\text { Risk-Reducing Surgery }\end{array} \\
n(\%)\end{array}$} & \multicolumn{2}{|c|}{ Odds Ratios (95\% CI) } \\
\hline & & \multirow{2}{*}{ Unadjusted } & \multirow{2}{*}{ Adjusted } \\
\hline & & & \\
\hline \multicolumn{4}{|l|}{ Age } \\
\hline $45-50$ & $74(30.3)$ & Ref & Ref \\
\hline $51-55$ & $65(31.9)$ & $1.07(0.72-1.61)$ & $0.94(0.51-1.74)$ \\
\hline $56-60$ & $60(30.9)$ & $1.03(0.68-1.55)$ & $1.00(0.53-1.87)$ \\
\hline $66-70$ & $27(23.7)$ & $0.71(0.43-1.19)$ & $0.48(0.14-1.65)$ \\
\hline 71-75 & $15(19.5)$ & $0.56(0.30-1.04)$ & $0.29(0.06-1.50)$ \\
\hline \multicolumn{4}{|l|}{ Ethnicity } \\
\hline White (Any background) & $278(28.6)$ & Ref & Ref \\
\hline Other ethnic group & $11(28.2)$ & $0.98(0.48-2.00)$ & $1.16(0.38-3.50)$ \\
\hline \multicolumn{4}{|l|}{ Educational Attainment } \\
\hline Undergraduate degree & $59(24.1)$ & $0.99(0.53-1.87)$ & \\
\hline Postgraduate degree & $28(30.4)$ & $1.37(0.67-2.80)$ & \\
\hline Other & $8(40.0)$ & $2.08(0.72-6.00)$ & \\
\hline
\end{tabular}


Table 2. Cont.

\begin{tabular}{|c|c|c|c|}
\hline \multirow{3}{*}{$\begin{array}{c}\text { Variable } \\
\text { Demographic Factors }\end{array}$} & \multirow{3}{*}{$\begin{array}{c}\begin{array}{c}\text { Intention to Have } \\
\text { Risk-Reducing Surgery }\end{array} \\
n(\%)\end{array}$} & \multicolumn{2}{|c|}{ Odds Ratios (95\% CI) } \\
\hline & & \multirow{2}{*}{ Unadjusted } & \multirow{2}{*}{ Adjusted } \\
\hline & & & \\
\hline \multicolumn{4}{|l|}{ Relationship Status } \\
\hline Not married/in a relationship & $82(27.1)$ & Ref & \\
\hline Married/in a relationship & $207(29.2)$ & $1.11(0.82-1.50)$ & \\
\hline Regular & $200(34.2)$ & Ref & Ref \\
\hline Irregular & $49(22.1)$ & $0.59(0.41-0.85)^{*}$ & $0.67(0.41-1.11)$ \\
\hline \multicolumn{4}{|c|}{ Breast Screening Attendance $(n=741)$} \\
\hline Regular & 205 (34.6) & Ref & Ref \\
\hline Irregular & $35(23.6)$ & $0.53(0.36-0.80) *$ & $0.67(0.38-1.17)$ \\
\hline \multicolumn{4}{|c|}{ Extended Parallel Processing Model Variables } \\
\hline Perceived Risk & & $1.43(1.19-1.71) * *$ & $1.14(0.90-1.45)$ \\
\hline Perceived Severity & & $1.42(1.11-1.82) *$ & $1.08(0.74-1.57)$ \\
\hline Self-Efficacy & & $2.19(1.94-2.47) * *$ & $1.90(1.63-2.22) * *$ \\
\hline Perceived Response Efficacy & & $3.15(2.50-3.96) * *$ & $2.22(1.64-3.00) * *$ \\
\hline \multicolumn{4}{|l|}{ Experimental condition } \\
\hline 5\% SNPs \& Lifestyle & $95(32.8)$ & Ref & Ref \\
\hline $10 \%$ SNPS \& Lifestyle & $90(31.0)$ & $0.92(0.66-1.29)$ & $1.08(0.67-1.73)$ \\
\hline $10 \%$ rare genetic variant & $105(36.2)$ & $1.18(0.85-1.65)$ & $1.87(1.17-3.00) * *$ \\
\hline
\end{tabular}

** Predictor significant at the 0.01 level (2-tailed), ${ }^{*}$ Predictor significant at the 0.05 level (2-tailed), CI = Confidence Interval. Ref = reference category.

\section{Discussion}

A high proportion (83\%) of women in this sample indicated they would be interested in having an ovarian cancer risk assessment if offered by their GP on the NHS. This is consistent with previous research by Meisel et al. (2016), who found that $88 \%$ of a general population sample of women in the UK would be interested in genetic testing for ovarian cancer risk if it were offered by the NHS, and included information about breast cancer risk, echoing previous support from qualitative research for the availability of genetic testing and risk-stratified screening [43]. It is also consistent with uptake of genetic testing in our population-based studies [12,21].

We also found that a substantial proportion of British women over the age of 45 years might be open to the idea of having RRSO, even if their absolute lifetime risk were increased from a general population risk of $2 \%$ to as little as $5 \%$ or $10 \%$. In addition, we also demonstrated in multivariable analyses that perceptions of risk-reducing surgery (self-efficacy and perceived response-efficacy) were independently associated with choosing surgery over other options, whereas the perceived threat of ovarian cancer (perceived risk and perceived severity) was not.

Although over a quarter $(29 \%)$ of women opted for RRSO, slightly more women opted for surveillance $(34 \%)$. The observed preference for surveillance may be due to the invasiveness of surgery, and could also potentially be due to the generally positive attitude towards cancer screening in the UK [44]. Lack of detailed information on the efficacy of each risk management option due to the hypothetical nature of this study may have resulted in participants deciding on the less invasive option, i.e., surveillance. Research suggests perceptions about risk-reducing surgery and surveillance are potentially modifiable: Mai et al. (2017) identified misperceptions about ovarian cancer risk and benefits of screening as important factors influencing decisions about risk-reducing surgery versus surveillance [45]. The concept of common genetic variants of low penetrance single nucleotide polymorphisms (SNPs) may be unfamiliar to the majority of individuals in the general public. For example, in a study by French et al. (2018), there was considerable variation in understanding of test results. The role of SNPs in cancer risk may be less familiar to individuals than more widely publicised 
rare genetic variants such as those in the BRCA genes [40]. Additionally, lifestyle factors may be perceived as being under greater personal control and, therefore, less serious than rare genetic variants.

Our study findings suggest that individuals interpreted the two levels of risk (5\% vs. 10\%) similarly, with the difference in communicated risk having a non-significant impact on participants' intentions to have RRSO. This supports previous research exploring the effect of risk information on behaviour, suggesting there is not a simple linear relationship between increments in risk and risk perception $[39,40]$.

In addition to the lack of impact on perceived risk of ovarian cancer, we similarly found that different presentations of risk in the hypothetical scenarios (5\% SNPs + lifestyle vs. 10\% SNPs + lifestyle risk; $10 \%$ rare genetic variant vs. $10 \%$ SNPs + lifestyle) did not lead to differences in any other cognitive factors considered in the EPPM framework (i.e., perceived severity of ovarian cancer, perceived response-efficacy of risk-reducing surgery, self-efficacy to undertake risk-reducing surgery).

In contrast, we found that, in the sample overall, opting for risk-reducing surgery was associated with higher self-efficacy and higher perceived response-efficacy of risk-reducing surgery. According to the Extended Parallel Processing Model [46], higher perceptions of self-efficacy and/or response-efficacy relating to the recommended behaviour are associated with greater likelihood that systematic processing of threatening (risk) information will occur. Conversely, when perceptions of efficacy are low, people are more likely to avoid threatening risk information. Together, our findings suggest that if women perceive or believe that RRSO is being recommended to them clinically, this may have a greater impact on their decision-making than the details of their risk result (i.e., whether their risk is $5 \%$ or $10 \%$, and whether that risk is based on a single rare genetic variant or a more complex combination of SNPs and lifestyle factors). The observation that psychological variables had a greater impact on intentions than the absolute risk numbers suggest that this might be important to consider in any potential future national rollouts. Offering psychological support for those who need it as part of the RRSO discussion and decision-making process is part of routine clinical practice in many centres today. Our study highlights the importance of incorporating this into future national guidelines.

In previous research using hypothetical scenarios, there has been some evidence to suggest that genetic information leads to more deterministic responses than non-genetic information [33,38,47-49]. Our study did not include a non-genetic condition and so does not speak to this aspect of how people respond to personal genetic versus non-genetic information.

The present study had several limitations. The cross-sectional design of the study did not allow for causation to be inferred. However, exploratory experimental studies such as this one can be valuable in informing hypotheses before moving on to study designs designed to trial real risk assessments. The use of hypothetical scenarios was both a strength and a limitation. This study attempted to model a "real life" scenario in which genetic risk information was provided to the general population. However, many of the contextual details and additional resources that accompany risk information are not available in hypothetical scenarios, which may limit the ecological validity of the study. This study was concerned with behavioural intention, as ovarian cancer population surveillance or population-wide genetic testing is not currently clinically available, so actual behaviour could not be measured. The presence of a potential intention behaviour gap is well established for other clinical interventions and cannot be excluded here.

The measures used in this study are adapted from previous research; however, they were almost all single-item measures, which may not be sensitive enough to adequately represent the underlying construct being measured due to the lack of psychometric information (e.g., test-retest reliability, discriminant or convergent validity). Prior knowledge may have an influence on how individuals appraise threatening health information [50]: this study did not measure previous ovarian cancer and genetic risk knowledge or previous genetic testing, which may have had an impact on behavioural intention (however this may be unlikely given this type of genetic testing is not widely available in the UK). In addition, we did not assess understanding of the information provided, and it is possible that some concepts (e.g., SNPs) may not have been well understood. 
The sample was predominately White British and, therefore, may not be generalisable to other ethnic groups, given decisions about risk-reducing surgery and psychological effects may differ cross-culturally. In addition, the restricted age-range of the sample limits the generalisability of the findings (e.g., to younger women age 35 years and over who may also be offered risk-reducing surgery if they are at high risk). However, most women from the general population who are at increased risk of ovarian cancer will fall in the intermediate risk (5-10\% lifetime risk) category [9]. RRSO at intermediate ovarian cancer risk levels (including for moderate penetrance CSGs) is recommended to be undertaken over the age of 45-50 years [15]. The sample was self-selected and may have had greater interest in the topic than the wider general population; the generalizability of the findings is therefore uncertain. Finally, as with any experimental study, we are unable to rule out the possibility of demand characteristics, i.e., participants responding in a way they think is expected according to their perceptions of the aim of the study. Despite the limitations, this study provides insights on the effects of experimentally manipulating genetic risk information for ovarian cancer on outcomes, comparing different sources and levels of risk on risk management behavioural intentions and psychological variables in the general population.

The information provided before being exposed to the hypothetical risk scenario on ovarian cancer, risk factors, and the efficacy of risk management was necessarily basic and brief, which may be an additional limitation. However, previous research did not find any difference in behavioural outcomes between use of gist and extended versions of decision aids in relation to ovarian cancer risk management [51]. Future research might usefully provide more detailed information containing details about the efficacy of a particular risk management behaviour to encourage "danger control" cognitive processing. This may aid in changing risk management preferences.

Future research might also benefit from including measures of other psychological and cognitive factors as potential predictors of risk management, e.g., causal beliefs. In addition, further research is needed on communicating risk information incorporating genetics to people in the general population outside of traditional clinical genetics department settings. Furthermore, a control group where participants are given a general population-based risk estimate would be useful for future research, as we were unable to compare between the general population risk and increased risk in this study.

The mean age of participants in this study was 57 years, with the majority of participants having completed having children and/or being past childbearing age, with most participants reporting they had begun menopause or were post-menopausal. Future research should explore the psychological and cognitive effects of ovarian cancer risk information being offered to younger women. In addition, there were relatively few women in the oldest age group (71-75 years) in this study, and so it is possible the apparent trend of increasing age being less associated with interest in surgery was due to the study being underpowered. This could also be a topic of investigation in future research.

Risk-reducing surgery, specifically RRSO, is at present the most effective risk management option available to women at increased risk of ovarian cancer. Our findings suggest there are a number of cognitive factors that influence intention to have ovarian cancer risk-reducing clinical interventions, beyond perceptions of risk. Future research should explore other possible factors that may have an impact on decision-making about risk management strategies. It is imperative to identify whether and/or how genetic risk information about common complex diseases will be translated into public health benefit: this is arguably especially urgent for diseases, such as ovarian cancer, which are characterised by being notoriously difficult to detect early and by having a high prevalence of late-stage diagnosis. Combined testing for multiple genetic factors together with lifestyle and other risk factors may lead to the ability to stratify the population for ovarian cancer risk for targeted prevention thus potentially saving lives.

Population testing provides a new paradigm for ovarian cancer prevention and can prevent thousands more cancers than the current clinical approach [52]. Jewish population studies support population testing for CSGs [53]. Our pilot study shows that population testing for lifetime risk of ovarian cancer is feasible, acceptable and has high satisfaction in general population women [12]. 
However, there is now need for large implementation studies, with long term outcomes, to provide real world evidence and develop context-specific models for implementing this approach for women in the general population. This will valuably inform future policy decisions regarding population-wide risk stratified approaches for risk-adapted ovarian cancer screening and prevention.

\section{Materials and Methods}

\subsection{Overview}

Participants $(n=1017)$ were women aged $45-75$ years recruited via online survey company Survey Sampling International (SSI) in July 2017. An email containing a web link was sent to SSI panellists who fit the study criteria with respect to gender and age, inviting them to take part. The email did not contain information about the topic of the study. Those responding were directed to a short screening questionnaire. Eligible participants were then presented with a consent form. Incentive points, which can be exchanged for shopping vouchers, were awarded to SSI panellists for their time (equivalent to $\sim £ 0.50$ for this 10 min study).

All participants were given information about ovarian cancer, including that on average around $2 \%$ of women will develop ovarian cancer in their lifetime; asked to imagine that they had had an ovarian cancer risk assessment via the NHS; and asked to imagine they had received a result indicating they were at increased risk of ovarian cancer (see Appendix A).

Women were randomly assigned to one of three experimental conditions using a software algorithm (See Figure 1). They were asked to imagine they had undergone an ovarian cancer risk assessment and had received this personalised risk estimate from their GP: (a) 5\% ovarian cancer risk due to common genetic variants and lifestyle factors; (b) 10\% ovarian cancer risk due to common genetic variants and lifestyle factors; or (c) 10\% ovarian cancer risk due to a single rare variant in a cancer susceptibility gene such as BRCA2 (see Appendix B).

The study was approved by the University College London ethics committee (Project ID Number: 10251/001).

\subsection{Inclusion Criteria}

Eligible participants were women aged 45-75 years, with no previous history of breast or ovarian cancer diagnosis. Women who indicated they were unsure of, or had not completed childbearing, were excluded from analyses $(n=13)$.

\subsection{Measures}

All measures are shown in Appendix C.

\subsubsection{Interest in Ovarian Cancer Risk Assessment}

Interest was assessed before exposure to the hypothetical test results, with the item, "If your GP offered you this ovarian cancer risk assessment on the NHS, would you take up the offer?" (adapted from [20]. Response options were "no, definitely not"; "no probably not"; "yes, probably" and "yes, definitely". The information women read before answering the question explained that the risk assessment would involve providing lifestyle information as well as a blood sample for genetic testing (see Appendix A).

\subsubsection{Perceived Risk of Ovarian Cancer}

Perceived risk was measured using a single item, "If I had just received this personal ovarian cancer risk result, I would feel that my risk of developing ovarian cancer was" adapted from [54]. Responses for these questions were recorded on a 5-point Likert scale with response options ranging from "much lower than other women of my age" to "much higher than women of my age". A higher score on the 5-point scale indicated greater perceived risk. 


\subsubsection{Perceived Severity of Ovarian Cancer}

Perceived severity was measured using two questions adapted from [55]: “Developing ovarian cancer would have major consequences on my life" and "ovarian cancer is a serious condition" with five response options ranging from "strongly agree" to "strongly disagree". A higher score on the (possible scores 1-5) scale indicated greater perceived severity.

\subsubsection{Self-Efficacy for Risk-Reducing Surgery}

One item, adapted from [56], assessed participants' confidence in their ability to have risk-reducing surgery. Individuals were asked "How confident are you that you would go through with risk-reducing surgery if you were motivated to do so". The response options ranged from "not at all confident" to "extremely confident". A higher score on the scale indicated greater perceived self-efficacy.

\subsubsection{Perceived Response-Efficacy of Risk-Reducing Surgery}

For perceived response-efficacy of risk-reducing surgery, participants were asked to indicate how effective they felt risk-reducing surgery would be in lowering their ovarian cancer risk using a single item adapted from [56]: "Having surgery to remove your ovaries and fallopian tubes is an effective way to lower your risk of ovarian cancer". The response options were "strongly agree" to "strongly disagree". Items were reverse coded: a higher score on the (possible scores 1-5) scale indicated greater perceived response-efficacy.

\subsubsection{Behavioural Intention}

To assess women's potential behavioural reactions to their risk results, they were asked: "If I had just received this personal ovarian cancer risk result, I would choose to...". The response options were: "have risk-reducing surgery to remove my ovaries"; "have surveillance such as regular ultrasound scans"; "make lifestyle changes"; "do nothing"; and "I am not sure what I would do".

\subsubsection{Demographic and Health Characteristic Measures}

Information on demographics was collected from all participants including: age, ethnicity, educational attainment, relationship status, health characteristics, family history of cancer, personal history of cancer, menopause status, and breast and cervical screening attendance. Ethnicity (White vs. other ethnic group), menopause status (pre-menopausal vs. peri/post-menopause) and breast and cervical screening attendance (regular vs. irregular or not yet eligible) were dichotomised.

\subsection{Data Analyses}

A power calculation based on the primary binary outcome, intention to have risk-reducing surgery, taking into account group comparisons of three groups, suggested a sample size of 782 was required (medium effect size, power of $90 \%$, alpha of 0.05 ). All statistical analyses of the data were carried out using SPSS 24. Analyses of variance (ANOVAs) and chi-square tests were conducted to explore between-group differences. Logistic regression was used to explore predictors of willingness to have risk-reducing surgery (vs. other behavioural responses to the risk information). Unadjusted and adjusted models were examined to explore the predictive effect of the experimental group and psychological variables on intention to have surgery and address possible demographic and health-related covariates.

\section{Conclusions}

The findings of this study contribute to a growing body of risk stratification research exploring the potential usefulness and clinical utility of population-wide risk assessment incorporating genetic testing alongside other risk factors. The need for risk stratification is perhaps particularly urgent for diseases, such as ovarian cancer, where survival outcomes are poor and population-wide screening for 
the disease is not currently recommended. We provide initial evidence, suggesting that a substantial proportion of women aged 45 years and over are open to the idea of risk stratification and having surgery to reduce their risk of ovarian cancer in response to increased risk results, even if their absolute lifetime risk is only increased by a few percentage points in absolute terms. Our findings do not speak to other barriers that might prevent women's behavioural intentions or preferences being translated into actions-barriers such as lack of timely access to healthcare services.

Supplementary Materials: The following are available online at http://www.mdpi.com/2072-6694/12/12/3543/s1, Table S1: Data for Figure 3, Table S2: Mean EPPM variables by experimental group.

Author Contributions: Conceptualization, S.S. and J.W.; methodology, J.W., A.G., S.S., R.M.; formal analysis, A.G., J.W., S.S.; resources, I.J., R.M., J.W.; data curation, A.G., S.S., J.W.; writing—original draft preparation, A.G.; writing—review and editing, J.W., S.S., I.J., R.M.; visualization, A.G., J.W., S.S.; supervision, J.W., S.S., I.J., R.M.; project administration, A.G.; funding acquisition, J.W. All authors have read and agreed to the published version of the manuscript.

Funding: The fieldwork for this study was funded by Cancer Research UK as part of a programme grant awarded to Professor Jane Wardle.

Acknowledgments: We are grateful to the women who took part in the study.

Conflicts of Interest: Ian Jacobs is a Director and shareholder in Abcodia, Ltd., a company focused on biomarkers for early detection of cancer. He is a co-inventor of the Risk of Ovarian Cancer Algorithm, which has been licensed to Abcodia by Massachusetts General Hospital, and has a right to a royalty stream. The other authors declare no conflict of interest. The funders had no role in the design of the study; in the collection, analyses, or interpretation of data; in the writing of the manuscript, or in the decision to publish the results.

\section{Appendix A}

\section{Ovarian cancer and risk information}

\section{Section 1: Hypothetical scenario}

Please imagine that you have gone to your GP, and they have offered you a new approach to assessing your risk of developing ovarian cancer in the future. When your GP offered this to you, they gave you some written information to help you decide whether or not you want to have the risk assessment done. This information is below. Please read the information, and then answer the question that follows.

\section{Assessing ovarian cancer risk}

Ovarian cancer is the sixth most common cancer among women in the UK: $2 \%$ of women will be diagnosed with ovarian cancer during their lifetime. Ovarian cancer is caused by many genetic and non-genetic factors. Currently, ovarian cancer is often detected at a late stage because symptoms are hard to spot. This means that it is often very hard to treat effectively.

A new ovarian cancer risk assessment has been developed. This risk assessment combines lots of different types of information about you to estimate how likely you are to develop ovarian cancer in your lifetime. The types of information included in the risk assessment include lifestyle factors, rare genetic variants, and common genetic variants.

Lifestyle factors: Lifestyle factors that may increase a woman's risk of ovarian cancer include tobacco smoking and being overweight.

Common genetic variants: Single nucleotide polymorphisms, frequently called SNPs (pronounced "snips"), are the most common type of genetic variation among people. SNPs occur normally throughout a person's DNA. Most SNPs have no effect on health, but some are important to a person's health. Some SNPs can influence a woman's risk of developing ovarian cancer. Individually, each one of these SNPs only influences ovarian cancer risk by a tiny amount, but if a woman has a large number of these SNPs then her risk of ovarian cancer may be increased.

Rare genetic variants: Some ovarian cancers are caused by a rare variant in a person's DNA. These rare variants can have quite a strong effect on a woman's risk of developing ovarian cancer. For example, variants in the BRCA2 gene can increase a woman's lifetime risk of ovarian cancer up to between $10 \%$ and $20 \%$. If you want to have this ovarian cancer risk assessment carried out, you will need to provide your GP with the information they request, including about your lifestyle. You will also need to have a blood test, so that the scientists can see whether you have any of the genetic variants that increase your risk. 


\section{Appendix B}

\section{Generic Risk Scenarios}

Next, regardless of how you answered in the previous question, please imagine that you have had the ovarian cancer risk assessment done, and your GP has now given you the result from the assessment. Please read your hypothetical result below.

Your personal ovarian cancer risk assessment: results [Group 1 only]

Your result indicates that your lifetime risk of developing ovarian cancer is $\underline{5 \%}$. This is higher than the average risk for women, which is $2 \%$.

Your risk of ovarian cancer is higher than average because you have been found to have at least one lifestyle factor and several common genetic variants which are known to put women at increased risk of developing ovarian cancer.

\section{OR}

Your personal ovarian cancer risk assessment: results [Group 2 only]

Your result indicates that your lifetime risk of developing ovarian cancer is $10 \%$. This is higher than the average risk for women, which is $2 \%$.

Your risk of ovarian cancer is higher than average because you have been found to have at least one lifestyle factor and several common genetic variants which are known to put women at increased risk of developing ovarian cancer.

$O R$

Your personal ovarian cancer risk assessment: results [Group 3 only]

Your result indicates that your lifetime risk of developing ovarian cancer is $10 \%$. This is higher than the average risk for women, which is $2 \%$.

Your risk of ovarian cancer is higher than average because you have been found to have a rare genetic variant which is known to put women at increased risk of developing ovarian cancer.

\section{AND}

\section{[All groups]}

There are several options for women who are at higher than average risk of ovarian cancer.

Risk-reducing surgery involves removing the ovaries and fallopian tubes to prevent ovarian cancer from developing. However, removing the ovaries has downsides. For example, it causes a woman who has not yet been through her menopause to start her menopause (a natural process that usually happens in a woman's early $50 \mathrm{~s}$ ).

Surveillance includes having a regular (e.g., annual) ultrasound of your ovaries to see if a tumour is present. This ultrasound is usually an internal (transvaginal) ultrasound. Effective screening has not been established. Lifestyle changes include maintaining a healthy weight and quitting smoking. These types of lifestyle changes may reduce a woman's risk of developing ovarian cancer.

\section{Appendix C}

\section{Questionnaire}

Please carefully imagine what you would think and how you would feel if you had received this personal result from the ovarian cancer risk assessment. Now please answer the following questions.

\section{Intention for Genetic Screening}

Q1. If your GP offered you this ovarian cancer risk assessment on the NHS, would you take up the offer? 
- No definitely not

- No probably not

- Yes probably

- Yes definitely

Q2. How likely do you think you are to develop ovarian cancer in your lifetime?
(a) $\quad \ldots$ Not at all likely
(b) ... Not very likely
(c) ... Quite likely
(d) ... Extremely likely

\section{Behavioural outcome}

Q3. If I had just received this personal ovarian cancer risk result, I would choose to ...
(a) $\ldots$ have risk-reducing surgery to remove my ovaries.
(b) ... have surveillance such as regular ultrasound scans.
(c) ... make lifestyle changes.
(d) $\ldots$ do nothing.
(e) ... I am not sure what I would choose.
(Please select one option only)

\section{Perceived risk}

Q4. If I had just received this personal ovarian cancer risk result, I would feel that my risk of developing ovarian cancer was...
(a) ... much lower than other women of my age
(b) $\ldots$ lower than other women of my age
(c) $\ldots$ the same as other women of my age
(d) $\ldots$ higher than other women of my age
(e) ... much higher than other women of my age

Perceived Response efficacy received this personal ovarian cancer risk result from the ovarian cancer risk assessment.

Q7. There is little that can be done to prevent ovarian cancer.
(a) ... Strongly agree
(b) $\ldots$ Agree
(c) ... Neither agree or disagree
(d) $\ldots$ Disagree
(e) ... Strongly disagree

Q8. Having surgery to remove your ovaries and fallopian tubes is an effective way to lower your risk of ovarian cancer.
(a) ... Strongly agree
(b) $\ldots$ Agree
(c) $\ldots$ Neither agree or disagree
(d) $\ldots$ Disagree
(e) ... Strongly disagree 
Perceived Response efficacy

Q9. Regular screening through transvaginal ultrasound is an effective way to lower your risk of ovarian cancer.
(a) ... Strongly agree
(b) ... Agree
(c) ... Neither agree or disagree
(d) $\ldots$ Disagree
(e) ... Strongly disagree

Perceived severity

Q10. Developing ovarian cancer would have major consequences on my life
(a) ... Strongly agree
(b) ... Agree
(c) ... Neither agree or disagree
(d) $\ldots$ Disagree
(e) ... Strongly disagree

Perceived severity

Q11. Ovarian cancer is a serious condition.
(a) ... Strongly agree
(b) ... Agree
(c) ... Neither agree or disagree
(d) $\ldots$ Disagree
(e) ... Strongly disagree

Self-efficacy

Q12. How confident are you that you could go through with having risk-reducing surgery if you were motivated to do so?
(a) $\quad \ldots$ not at all confident
(b) $\ldots$ somewhat confident
(c) $\ldots$ fairly confident
(d) $\ldots$ very confident
(e) ... extremely confident

Q13. Have you ever been diagnosed with cancer? (Please select one)

Yes

No

Not sure

Q14. If yes, what type of cancer is it/was it?

Q15. Do you have a family history of cancer?

Have anyfirst-degree family member(parents, brothers, sisters, children) orsecond-degree(aunts, uncles, nieces, nephews, grandparents, grandchildren) been diagnosed with cancer.

Yes 
No

Not sure

Q15a. If yes, what type(s) of cancer?

Q16. What is your current menstrual status? (Please select one)

Premenopausal (before menopause; having regular periods)

Perimenopause (menopause transition—changes in periods, but have not gone 12 months in a row without a period)

Postmenopausal (After menopause; periods have stopped for at least 12 months)

Don't know

Q17. If you have indicated that you have not had a period in the previous 12 months, what age were you at your last period?

Q18. If you are still having periods, how often do they occur? (Please respond in days)

Q19. Is there a recent change in how often you have periods?

Yes/No

Q20. Was your menopause:

Spontaneous ("natural")

Surgical (removal of both ovaries)

Due to chemotherapy or radiation therapy

Other

n/a-haven't yet reached menopause

(If indicated they are still having periods don't ask this question)

Q21. Women aged 25-49 years are invited for cervical screening (also called a smear or Pap test) every 3 years, and women aged 50-64 are invited every 5 years. Which of these statements best describes you?

I'm up to date with cervical screening

I'm overdue for cervical screening

I've never been for cervical screening

I'm 65 or over so I'm not invited any more

Q22. Women aged 50-70 years are invited for breast screening (also called a mammogram or mammography) every 3 years. Which of these statements best describes you?

I'm up to date with breast screening

I'm overdue for breast screening

I've never been for breast screening

$I^{\prime} m$ under 50 or over 70 so I'm not eligible for breast screening.

Q23. How old are you?

Q24. How would you describe your ethnic background? (Please select one)

White British

White non-British 
Black

Asian

Mixed

Other

Do not wish to answer

Q25. What is the highest level of education you have achieved? (Please select one)

No formal qualifications

GCSEs/O levels or equivalent

A-Levels or equivalent

Undergraduate degree or equivalent

Postgraduate degree or equivalent

Other (please state)

Q26. What is your relationship status? (Please select one)

Single

In a relationship

Living with a partner

Married

Separated/divorced/widowed

Q27. How many children do you have? (Please select one)

0

1

2

3

4

5 or more

Q28. Do you plan to have any (more) children in the future? (Please select one)

Yes

No

Not sure

\section{END OF SURVEY}

\section{References}

1. Cancer Research UK, Ovarian Cancer Statistics. 2016. Available online: https://www.cancerresearchuk.org/ health-professional/cancer-statistics/statistics-by-cancer-type/ovarian-cancer (accessed on 25 June 2017).

2. Hunn, J.; Rodriguez, G.C. Ovarian Cancer: Etiology, risk factors, and epidemiology. Clin. Obstet. Gynecol. 2012, 55, 3-23. [CrossRef] [PubMed]

3. Levy-Lahad, E.; Gabai-Kapara, E.; Kaufman, B.; Catane, R.; Segev, S.; Renbaum, P.; Beller, U.; King, M.; Lahad, A. Identification of BRCA1/BRCA2 carriers by screening in the healthy population and its implications. J. Clin. Oncol. 2011, 29, 1513. [CrossRef]

4. King, M.-C.; Levy-Lahad, E.; Lahad, A. Population-Based Screening for BRCA1 and BRCA2. JAMA 2014, 312, 1091-1092. [CrossRef] [PubMed]

5. Kuchenbaecker, K.B.; Hopper, J.L.; Barnes, D.R.; Phillips, K.-A.; Mooij, T.M.; Roos-Blom, M.-J.; Jervis, S.E.; Van Leeuwen, F.; Milne, R.L.; Andrieu, N.; et al. Risks of Breast, Ovarian, and Contralateral Breast Cancer for BRCA1 and BRCA2 Mutation Carriers. JAMA 2017, 317, 2402-2416. [CrossRef] [PubMed] 
6. $\quad$ Manchanda, R.; Burnell, M.; Gaba, F.; Desai, R.; Wardle, J.; Gessler, S.; Side, L.; Sanderson, S.; Loggenberg, K.; Brady, A.F.; et al. Randomised trial of population-based BRCA testing in Ashkenazi Jews: Long-term outcomes. BJOG: Int. J. Obstet. Gynaecol. 2019, 127, 364-375. [CrossRef] [PubMed]

7. Manchanda, R.; Loggenberg, K.; Sanderson, S.; Burnell, M.; Wardle, J.; Gessler, S.; Side, L.; Balogun, N.; Desai, R.; Kumar, A.; et al. Population testing for cancer predisposing BRCA1/BRCA2 mutations in the Ashkenazi-Jewish community: A randomized controlled trial. J. Natl. Cancer Inst. 2014, 107, 379. [CrossRef]

8. Manchanda, R.; Blyuss, O.; Gaba, F.; Gordeev, V.S.; Jacobs, C.; Burnell, M.; Gan, C.; Taylor, R.; Turnbull, C.; Legood, R.; et al. Current detection rates and time-to-detection of all identifiable BRCA carriers in the Greater London population. J. Med. Genet. 2018, 55, 538-545. [CrossRef]

9. Jervis, S.; Song, H.; Lee, A.; Dicks, E.; Harrington, P.; Baynes, C.; Manchanda, R.; Easton, D.F.; Jacobs, I.; Pharoah, P.P.D.; et al. A risk prediction algorithm for ovarian cancer incorporating BRCA1, BRCA2, common alleles and other familial effects. J. Med. Genet. 2015, 52, 465-475. [CrossRef]

10. Manchanda, R.; Gaba, F. Population Based Testing for Primary Prevention: A Systematic Review. Cancers 2018, 10, 424. [CrossRef]

11. Evans, O.; Gaba, F.; Manchanda, R. Population-based genetic testing for Women's cancer prevention. Best Pr. Res. Clin. Obstet. Gynaecol. 2020, 65, 139-153. [CrossRef]

12. Gaba, F.; Blyuss, O.; Liu, X.; Goyal, S.; Lahoti, N.; Chandrasekaran, D.; Kurzer, M.; Kalsi, J.K.; Sanderson, S.C.; Lanceley, A.; et al. Population Study of Ovarian Cancer Risk Prediction for Targeted Screening and Prevention. Cancers 2020, 12, 1241. [CrossRef] [PubMed]

13. Rahman, B.; Side, L.; Gibbon, S.; Meisel, S.F.; Fraser, L.; Gessler, S.; Wardle, J.; Lanceley, A. Moving towards population-based genetic risk prediction for ovarian cancer. BJOG: Int. J. Obstet. Gynaecol. 2017, 124, 855-858. [CrossRef]

14. Manchanda, R.; Legood, R.; Antoniou, A.; Pearce, L.; Menon, U. Commentary on changing the risk threshold for surgical prevention of ovarian cancer. BJOG: Int. J. Obstet. Gynaecol. 2017, 125, 541-544. [CrossRef] [PubMed]

15. Manchanda, R.; Menon, U. Setting the Threshold for Surgical Prevention in Women at Increased Risk of Ovarian Cancer. Int. J. Gynecol. Cancer 2018, 28, 34-42. [CrossRef] [PubMed]

16. Manchanda, R.; Legood, R.; Antoniou, A.C.; Gordeev, V.S.; Menon, U. Specifying the ovarian cancer risk threshold of 'premenopausal risk-reducing salpingo-oophorectomy' for ovarian cancer prevention: A cost-effectiveness analysis. J. Med. Genet. 2016, 53, 591-599. [CrossRef] [PubMed]

17. Manchanda, R.; Legood, R.; Pearce, L.; Menon, U. Defining the risk threshold for risk reducing salpingo-oophorectomy for ovarian cancer prevention in low risk postmenopausal women. Gynecol. Oncol. 2015, 139, 487-494. [CrossRef] [PubMed]

18. Manchanda, R.; Patel, S.; Gordeev, V.S.; Antoniou, A.C.; Smith, S.; Lee, A.; Hopper, J.L.; MacInnis, R.J.; Turnbull, C.G.N.; Ramus, S.J.; et al. Cost-effectiveness of Population-Based BRCA1, BRCA2, RAD51C, RAD51D, BRIP1, PALB2 Mutation Testing in Unselected General Population Women. J. Natl. Cancer Inst. 2018, 110, 714-725. [CrossRef]

19. Chandrasekaran, D.; Manchanda, R. Germline and somatic genetic testing in ovarian cancer patients. BJOG: Int. J. Obstet. Gynaecol. 2018, 125, 1460. [CrossRef]

20. Meisel, S.F.; for the PROMISE-2016 Study Team; Rahman, B.; Side, L.; Fraser, L.; Gessler, S.; Lanceley, A.; Wardle, J. Genetic testing and personalized ovarian cancer screening: A survey of public attitudes. BMC Women's Health 2016, 16, 46. [CrossRef]

21. Manchanda, R.; Burnell, M.; Loggenberg, K.; Desai, R.; Wardle, J.; Sanderson, S.C.; Gessler, S.; Side, L.; Balogun, N.; Kumar, A.; et al. Cluster-randomised non-inferiority trial comparing DVD-assisted and traditional genetic counselling in systematic population testing for BRCA1/2 mutations. J. Med. Genet. 2016, 53, 472-480. [CrossRef]

22. Manchanda, R.; Legood, R.; Burnell, M.; McGuire, A.; Raikou, M.; Loggenberg, K.; Wardle, J.; Sanderson, S.; Gessler, S.; Side, L.; et al. Cost-effectiveness of Population Screening for BRCA Mutations in Ashkenazi Jewish Women Compared with Family History-Based Testing. J. Natl. Cancer Inst. 2015, 107, 380. [CrossRef] [PubMed]

23. Manchanda, R.; Patel, S.; Antoniou, A.C.; Levy-Lahad, E.; Turnbull, C.; Evans, D.G.; Hopper, J.L.; MacInnis, R.J.; Menon, U.; Jacobs, I.; et al. Cost-effectiveness of population based BRCA testing with varying Ashkenazi Jewish ancestry. Am. J. Obstet. Gynecol. 2017, 217, 578.e1-578.e12. [CrossRef] [PubMed] 
24. Rebbeck, T.R.; Lynch, H.T.; Neuhausen, S.L.; Narod, S.A.; Veer, L.V.; Garber, J.E.; Evans, G.; Isaacs, C.; Daly, M.B.; Matloff, E.; et al. Prophylactic Oophorectomy in Carriers of BRCA1 or BRCA2 Mutations. N. Engl. J. Med. 2002, 346, 1616-1622. [CrossRef] [PubMed]

25. Manchanda, R.; Burnell, M.; Abdelraheim, A.; Johnson, M.; Sharma, A.; Benjamin, E.; Brunell, C.; Saridogan, E.; Gessler, S.; Oram, D.; et al. Factors influencing uptake and timing of risk reducing salpingo-oophorectomy in women at risk of familial ovarian cancer: A competing risk time to event analysis. BJOG: Int. J. Obstet. Gynaecol. 2012, 119, 527-536. [CrossRef]

26. Manchanda, R.; Abdelraheim, A.; Johnson, M.; Rosenthal, A.N.; Benjamin, E.; Brunell, C.; Burnell, M.; Side, L.; Gessler, S.; Saridogan, E.; et al. Outcome of risk-reducing salpingo-oophorectomy in BRCA carriers and women of unknown mutation status. BJOG: Int. J. Obstet. Gynaecol. 2011, 118, 814-824. [CrossRef]

27. Yang, X.; Song, H.; Leslie, G.; Engel, C.; Hahnen, E.; Auber, B.; Horváth, J.; Kast, K.; Niederacher, D.; Turnbull, C.; et al. Ovarian and Breast Cancer Risks Associated with Pathogenic Variants in RAD51C and RAD51D. J. Natl. Cancer Inst. 2020. [CrossRef]

28. Yang, X.; Leslie, G.; Doroszuk, A.; Schneider, S.; Allen, J.; Decker, B.; Dunning, A.M.; Redman, J.; Scarth, J.; Plaskocinska, I.; et al. Cancer Risks Associated with Germline PALB2 Pathogenic Variants: An International Study of 524 Families. J. Clin. Oncol. 2020, 38, 674-685. [CrossRef]

29. Ramus, S.J.; Song, H.; Dicks, E.; Tyrer, J.P.; Rosenthal, A.N.; Intermaggio, M.P.; Fraser, L.; Gentry-Maharaj, A.; Hayward, J.; Philpott, S.; et al. Germline Mutations in the BRIP1, BARD1, PALB2, and NBN Genes in Women with Ovarian Cancer. J. Natl. Cancer Inst. 2015, 107. [CrossRef]

30. Jacobs, I.; Menon, U.; Ryan, A.; Gentry-Maharaj, A.; Burnell, M.; Kalsi, J.K.; Amso, N.N.; Apostolidou, S.; Benjamin, E.; Cruickshank, D.; et al. Ovarian cancer screening and mortality in the UK Collaborative Trial of Ovarian Cancer Screening (UKCTOCS): A randomised controlled trial. Lancet 2016, 387, 945-956. [CrossRef]

31. Rosenthal, A.N.; Fraser, L.S.; Philpott, S.; Manchanda, R.; Burnell, M.; Badman, P.; Hadwin, R.; Rizzuto, I.; Benjamin, E.C.; Singh, N.; et al. Evidence of Stage Shift in Women Diagnosed with Ovarian Cancer during Phase II of the United Kingdom Familial Ovarian Cancer Screening Study. J. Clin. Oncol. 2017, 35, 1411-1420. [CrossRef]

32. Kauff, N.D.; Domchek, S.M.; Friebel, T.M.; Robson, M.E.; Lee, J.; Garber, J.E.; Isaacs, C.; Evans, D.G.; Lynch, H.; Eeles, R.A.; et al. Risk-Reducing Salpingo-Oophorectomy for the Prevention of BRCA1- and BRCA2-Associated Breast and Gynecologic Cancer: A Multicenter, Prospective Study. J. Clin. Oncol. 2008, 26, 1331-1337. [CrossRef] [PubMed]

33. Hollands, G.J.; French, D.P.; Griffin, S.J.; Prevost, A.T.; Sutton, S.; King, S.; Marteau, T.M. The impact of communicating genetic risks of disease on risk-reducing health behaviour: Systematic review with meta-analysis. BMJ 2016, 352, i1102. [CrossRef] [PubMed]

34. Hallowell, N.; kConFab Psychosocial Group on Behalf of the kConFab Investigators; Baylock, B.; Heiniger, L.; Butow, P.N.; Patel, D.; Meiser, B.; Saunders, C.M.; Price, M.A. Looking different, feeling different: Women's reactions to risk-reducing breast and ovarian surgery. Fam. Cancer 2011, 11, 215-224. [CrossRef] [PubMed]

35. Meiser, B.; Butow, P.; Friedlander, M.; Barratt, A.; Schnieden, V.; Watson, M.; Brown, J.; Tucker, K. Psychological impact of genetic testing in women from high-risk breast cancer families. Eur. J. Cancer 2002, 38, 2025-2031. [CrossRef]

36. Pruthi, S.; Gostout, B.S.; Lindor, N.M. Identification and Management of Women with BRCA Mutations or Hereditary Predisposition for Breast and Ovarian Cancer. Mayo Clinic Proc. 2010, 85, 1111-1120. [CrossRef]

37. Rebbeck, T.R.; Kauff, N.D.; Domchek, S.M. Meta-analysis of Risk Reduction Estimates Associated with Risk-Reducing Salpingo-oophorectomy in BRCA1 or BRCA2 Mutation Carriers. J. Natl. Cancer Inst. 2009, 101, 80-87. [CrossRef]

38. Marteau, T.M.; French, D.P.; Griffin, S.J.; Prevost, T.; Sutton, S.; Watkinson, C.; Attwood, S.; Hollands, G.J. Effects of communicating DNA-based disease risk estimates on risk-reducing behaviours. Cochrane Database Syst. Rev. 2010, CD007275. [CrossRef]

39. Cameron, L.D.; Sherman, K.; Marteau, T.M.; Brown, P.M. Impact of genetic risk information and type of disease on perceived risk, anticipated affect, and expected consequences of genetic tests. Health Psychol. 2009, 28, 307-316. [CrossRef] 
40. French, D.P.; Southworth, J.; Howell, A.; Harvie, M.; Stavrinos, P.; Watterson, D.; Sampson, S.; Evans, D.G.; Donnelly, L.S. Psychological impact of providing women with personalised 10-year breast cancer risk estimates. Br. J. Cancer 2018, 118, 1648-1657. [CrossRef]

41. Hart, M.R.; Biesecker, B.B.; Blout, C.L.; Christensen, K.D.; Amendola, L.M.; Bergstrom, K.L.; Biswas, S.; Bowling, K.M.; Brothers, K.B.; Conlin, L.K.; et al. Secondary findings from clinical genomic sequencing: Prevalence, patient perspectives, family history assessment, and health-care costs from a multisite study. Genet. Med. 2019, 21, 1100-1110. [CrossRef]

42. Witte, K.; Allen, M. A Meta-Analysis of Fear Appeals: Implications for Effective Public Health Campaigns. Heal. Educ. Behav. 2000, 27, 591-615. [CrossRef] [PubMed]

43. Meisel, S.F.; Side, L.; Fraser, L.; Gessler, S.; Wardle, J.; Lanceley, A. Population-Based, Risk-Stratified Genetic Testing for Ovarian Cancer Risk: A Focus Group Study. Public Health Genom. 2013, 16, 184-191. [CrossRef] [PubMed]

44. Waller, J.L.; Osborne, K.; Wardle, J.F.C. Enthusiasm for cancer screening in Great Britain: A general population survey. Br. J. Cancer 2015, 112, 562-566. [CrossRef] [PubMed]

45. Mai, P.L.; Piedmonte, M.; Han, P.K.J.; Moser, R.P.; Walker, J.L.; Rodriguez, G.C.; Boggess, J.; Rutherford, T.J.; Zivanovic, O.; Cohn, D.E.; et al. Factors associated with deciding between risk-reducing salpingo-oophorectomy and ovarian cancer screening among high-risk women enrolled in GOG-0199: An NRG Oncology/Gynecologic Oncology Group study. Gynecol. Oncol. 2017, 145, 122-129. [CrossRef] [PubMed]

46. Witte, K. Putting the fear back into fear appeals: The extended parallel process model. Commun. Monogr. 1992, 59, 329-349. [CrossRef]

47. Claassen, L.; Henneman, L.; De Vet, R.; Knol, D.; Marteau, T.M.; Timmermans, D. Fatalistic responses to different types of genetic risk information: Exploring the role of Self-Malleability. Psychol. Health 2010, 25, 183-196. [CrossRef] [PubMed]

48. Marteau, T.M. Genetic risk and behavioural change. BMJ 2001, 322, 1056-1059. [CrossRef]

49. Marteau, T.M.; Weinman, J. Self-regulation and the behavioural response to DNA risk information: A theoretical analysis and framework for future research. Soc. Sci. Med. 2006, 62, 1360-1368. [CrossRef]

50. Evans, R.E.; Beeken, R.J.; Steptoe, A.; Wardle, J. Cancer information and anxiety: Applying the Extended Parallel Process Model. J. Health Psychol. 2012, 17, 579-589. [CrossRef]

51. Meisel, S.F.; Freeman, M.; Waller, J.; Fraser, L.; Gessler, S.; Jacobs, I.; Kalsi, J.K.; Manchanda, R.; Rahman, B.; Side, L.; et al. Impact of a decision aid about stratified ovarian cancer risk-management on women's knowledge and intentions: A randomised online experimental survey study. BMC Public Health 2017, 17, 882. [CrossRef]

52. Evans, O.; Manchanda, R. Population-based Genetic Testing for Precision Prevention. Cancer Prev. Res. 2020, 13, 643-648. [CrossRef] [PubMed]

53. Manchanda, R.; Lieberman, S.; Gaba, F.; Lahad, A.; Levy-Lahad, E. Population Screening for Inherited Predisposition to Breast and Ovarian Cancer. Annu. Rev. Genom. Hum. Genet. 2020, 21, 373-412. [CrossRef] [PubMed]

54. Gurmankin, A.D.; Shea, J.; Williams, S.V.; Quistberg, D.A.; Armstrong, K. Measuring Perceptions of Breast Cancer Risk. Cancer Epidemiol. Biomarkers Prev. 2006, 15, 1893-1898. [CrossRef] [PubMed]

55. Peipins, L.A.; Mccarty, F.; Hawkins, N.A.; Rodriguez, J.L.; Scholl, L.E.; Leadbetter, S. Cognitive and affective influences on perceived risk of ovarian cancer. Psycho-Oncology 2015, 24, 279-286. [CrossRef] [PubMed]

56. Rawl, S.; Champion, V.; Menon, U.; Loehrer, P.J.; Vance, G.H.; Skinner, C.S. Validation of Scales to Measure Benefits of and Barriers to Colorectal Cancer Screening. J. Psychosoc. Oncol. 2001, 19, 47-63. [CrossRef]

Publisher's Note: MDPI stays neutral with regard to jurisdictional claims in published maps and institutional affiliations. 